\title{
Acute closed-angle glaucoma and Nd-YAG laser iridotomy
}

\author{
D C Saunders
}

\begin{abstract}
Forty-one patients presenting consecutively with acute angle closure glaucoma (AACG) were studied with a median follow-up period of eight months. Four patients presented with bilateral symptoms. Thirty-nine patients underwent Nd-YAG laser iridotomy (42 AACG eyes and 36 fellow eyes). Only 15 patients $(36.6 \%)$ required simply iridotomy; the remainder required additional long term medical or surgical treatment. Longer duration of symptoms and a history of previous intermittent, spontaneously resolved AACG were more common in those requiring additional treatment. Cataract extraction with intraocular lens implantation was performed for three eyes with AACG, and this mode of treatment is discussed as a possible primary treatment. One eye with AACG suffered a second episode, and two fellow eyes developed AACG despite laser iridotomy. Possible mechanisms are discussed. Provocative testing or frequent careful observation of iridotomy patency is recommended.
\end{abstract}

This study was undertaken as an audit of a consecutive group of patients presenting with acute angle closure glaucoma (AACG) and to establish any prognostic indicators. To my knowledge only one previous study has assessed Nd-YAG laser iridotomy in AACG in more than 30 patients, ${ }^{1}$ and none have examined a consecutive group of patients.

\section{Patients and methods}

All patients attending Manchester Royal Eye Hospital with AACG between September 1987 and March 1988 were included. The diagnosis was suspected on the basis of a history of pain and blurring of vision and confirmed by finding a raised intraocular pressure (IOP), corneal oedema, a mid-dilated pupil, and a closed iridocorneal angle. The latter was identified either by gonioscopy or direct observation of iridocorneal contact on the slit-lamp. All patients were admitted to hospital and treated medically to break the acute attack. Treatment was with intravenous and oral acetazolamide (Diamox), pilocarpine 4\%, timolol, and topical steroid. Patients not responding promptly to this regimen were given intravenous mannitol. After the acute attack was controlled bilateral laser iridotomy was performed with the Lasag Neodymium YAG Series 2 Microruptor with CGIl or Abraham contact lens, and antiglaucoma medication was stopped. Iridotomy patency was assessed by direct visualisation of the lens capsule through the iridotomy and/or by the appearance of a plume of iris pigment during treatment. If the IOP was not adequately controlled, topical antiglaucoma medication was begun again. Trabeculectomy followed if the IOP remained uncontrolled.

\section{Results}

Forty-one patients presented during the course of the study (Table 1). Four patients suffered bilateral AACG, so 45 eyes with AACG and 37 fellow eyes were studied. There was an equal distribution of left and right eyes (23 OS, 22 OD). The average age of the patients was 70.5 years (range $45-89)$, and $31(75 \cdot 6 \%)$ were female. All were Caucasian.

Nine patients (22\%) gave a history of intermittent pain and blurring of vision or haloes, consistent with spontaneously resolved attacks of AACG. These had occurred from two weeks to 14 months prior to presentation with AACG. The duration of symptoms overall varied from 4 hours to 21 days (mean $4 \cdot 7$ days). Four patients with bilateral symptoms presented. Two had failed to seek medical advice for nine months following the involvement of the first eye (resulting in no perception of light), but presented promptly when the second eye became involved. One had similarly ignored the first eye for five days until the second eye was involved. One patient presented with simultaneous symptoms in both eyes.

The initial medical treatment, without mannitol, was sufficient to break the acute attack in $37(90 \%)$ patients. Four patients required mannitol, but in only two did it break the attack.

Extracapsular cataract extraction with IOL was performed in three patients, two of whom were still in angle closure with a raised IOP at the time of surgery, which was performed as an emergency. The third underwent surgery shortly after iridotomy. He was lost to follow-up, but initially did well with a corrected visual acuity (VA) of $6 / 9$ on no medication at three months. The other two patients did well with corrected VA $6 / 6$ and $6 / 9$ respectively and required no long term antiglaucoma medication. None showed signs of corneal decompensation, and there was no increased surgical morbidity.

Table 1 Acute closed-angle glaucoma treated with Nd-YAG laser iridotomy: demographic details

\begin{tabular}{llll}
\hline & Males & Females & Total \\
\hline Number & 10 & 31 & 41 \\
Mean age (yr) & $69 \cdot 8$ & $70 \cdot 7$ & $70 \cdot 5$ \\
Mean duration of symptoms & $5 \cdot 5$ days & $4 \cdot 5$ days & $4 \cdot 7$ days \\
Eyes: & & & \\
left & 4 & 15 & 19 \\
right & 5 & 13 & 18 \\
bilateral & 1 & 3 & 4 \\
total & 11 & 34 & 45 \\
\hline
\end{tabular}


Table 2 Acute closed-angle glaucoma treated with Nd-YAG laser iridotomy: surgery required

\begin{tabular}{ll}
\hline Operation & No. \\
\hline Trabeculectomy & 8 \\
Peripheral iridectomy & 4 \\
Extracapsular cataract extraction with IOL & 3 \\
Sector iridectomy & 1 \\
\hline
\end{tabular}

None of the three had mature intumescent lenses; all had nuclear sclerosis type cataract.

Cataract surgery was performed under retrobulbar anaesthesia with 3-4 ml of bupivacaine, lignocaine, and hyaluronidase. Digital massage was used following retrobulbar anaesthesia to lower the IOP. A corneal section was used, the eye being decompressed slowly by a small puncture prior to opening the section. Standard extracapsular extraction followed, aided by a viscoelastic substance which was used to deepen the anterior chamber. The nucleus was expressed with a vectis and soft lens matter removed with an aspiration/irrigation cannula. A posterior chamber IOL was inserted in the capsular bag. No peripheral iridectomy was performed. The section was sutured with 10/0 monofilament nylon. Subconjunctival betamethasone and gentamicin followed. Postoperatively a topical steroid, an antibiotic, and a mydriatic were given for four to six weeks.

One patient was too debilitated to undergo either laser treatment or surgery and was treated with long term pilocarpine.

Thus 42 out of 45 AACG eyes and 36 out of 37 fellow eyes underwent Nd-YAG laser iridotomy; a total of 78 eyes (95\%).

The Nd-YAG laser did not achieve a patent iridotomy in three patients (four eyes, two AACG and two fellow eyes), and these underwent surgical peripheral iridectomy (PI). Following surgical PI two eyes (same patient) required antiglaucoma medication. One eye suffered recurrent AACG on the first postoperative day and subsequently underwent sector iridectomy. Three $(7 \cdot 3 \%)$ patients suffered a second attack of AACG despite initially patent iridotomy. Two were treated with repeat $\mathrm{Nd}-\mathrm{YAG}$ laser iridotomy and one required trabeculectomy. The final VA was $6 / 9,6 / 18$, and counting fingers respectively. Fifteen patients $(36.5 \%)$ required no further treatment after Nd-YAG laser iridotomy, and a further nine required no treatment following surgery (total 24 patients, $58 \cdot 5 \%$ ).

Sixteen operations were required on 15 eyes of 14 patients. Table 2 gives details.

One patient was lost to follow-up, leaving 16 patients (39\%) needing antiglaucoma medication. The lost patient was on no medication at three months. At present the IOP is not controlled in one patient. Thus 39 patients $(95 \%)$ have controlled IOP.

Patients were divided into two groups: group $A$ required no long term antiglaucoma medication and no trabeculectomy, while group B required medication and/or trabeculectomy (Table 3). Thus group B represents patients with compromised angle function, whereas group A have adequate angle function. The mean duration of symptoms of group A was 3.52 days
Table 3 Acute closed-angle glaucoma treated with $N d-Y A G$ laser iridotomy: medication vs non-medication

\begin{tabular}{llllll}
\hline & $Y A G$ & $E C C E+I O L$ & $P I$ & Trabeculectomy & Total \\
\hline No treatment & 15 & $2+1^{\star}$ & 1 & 6 & $24+1^{\star}$ \\
\cline { 2 - 6 } Treatment & 12 & 0 & 2 & 2 & 16 \\
\hline
\end{tabular}

^Lost to follow-up; on no medication at 3 months. The underlined figures represent group A; the remainder are group $B$.

Table 4 Acute closed-angle glaucoma treated with Nd-YAG laser iridotomy: group $A$ vs group $B$

\begin{tabular}{lcc}
\hline & Group A & Group $B$ \\
\hline Mean duration of symptoms (days) & $3 \cdot 52$ & $5 \cdot 09$ \\
Median duration of symptoms (days) & 2 & $2 \cdot 5$ \\
Number with history of resolved AACG & $1 / 18$ & $8 / 22$ \\
Percentage with history of resolved AACG & $5 \cdot 6 \%$ & $36 \cdot 4 \%$ \\
Presenting IOP (mmHg) & $55 \cdot 6$ & $53 \cdot 4$ \\
\hline
\end{tabular}

(median 2 days), while for group B it was 5.09 days (median 2.5 days). This is a statistically significantly longer duration of symptoms in group B (rank sum test, $\mathrm{p}<0.01$ ). In group A only $1 / 18(6 \%)$ had a history of previously resolved AACG, whereas $8 / 22(36 \%)$ of group B had similar symptoms. The level of the IOP at presentation was not significantly different in the two groups (Table 4).

\section{Discussion}

The demographic details of the patients compare well with those found in other studies. ${ }^{2}$ The one eye which suffered recurrent AACG on the first postoperative day following surgical PI had been dilated with cyclopentolate by junior staff. Lowe $^{3}$ highlighted the dangers of tropine drugs for postoperative dilatation in these circumstances and recommended $10 \%$ phenylephrine as a safer alternative. ${ }^{4}$ Nonetheless, cases have been reported of recurrent AACG following surgical PI dilated with phenylephrine. ${ }^{45}$ The mechanism of this angle closure is iris crowding into the angle rather than pupil block. Thus the tropine drugs, as powerful dilators, are more dangerous than phenylephrine, a weak dilator. This type of angle closure tends to occur in eyes with 'plateau iris' - that is, with anterior insertion of the iris, a flat iris plane, and a nearly normal axial anterior chamber depth. 'Plateau iris' has been estimated to account for $6 \cdot 1 \%$ of eyes with AACG. ${ }^{6}$ This case serves as a reminder that, with the advent of laser iridotomy, surgical PI is undertaken only rarely for the treatment of AACG, and that junior staff may be unaware of the most appropriate postoperative management.

In this study duration of symptoms prior to presentation is significant in distinguishing between those patients who will be cured by simple iridotomy and those who will require additional medication or surgery. This is in accord with the findings of Hass and Scheie ${ }^{7}$ but at variance with those of Gray et al. ${ }^{\prime}$ It would appear reasonable that the longer an attack lasts, the greater the risk of peripheral anterior synechiae and/or angle damage. This reinforces the need for prompt lowering of IOP.

A past history suggestive of spontaneously resolved AACG appears to be significant in distinguishing the iridotomy-only group from the additional-treatment group. This may be a 
true reflection of angle damage and/or peripheral anterior synechiae formation during recurrent AACG, or it may simply lead to a longer period in AACG prior to presentation, as the patient awaits the expected spontaneous resolution. In fact the nine patients presenting with a history of previous symptoms had a significantly shorter duration of symptoms for the presenting episode than those without a previous history (rank sum test, $\mathrm{p}<0.01$ ). Thus it would appear that a previous history of resolved AACG is independently significant in identifying those patients who are likely to need additional treatment.

The major anatomical factors of AACG eyes depend on faulty co-ordination of lens size and position in relation to axial length. ${ }^{8}$ In a condition directly related to lens morphology and in which lens opacities may progress after the acute event (independently of intervention) ${ }^{29}$ it would seem reasonable to consider cataract extraction with IOL insertion as the primary surgical treatment if significant lens opacities are already present. In this way the anterior chamber is deepened, and the angle closure relieved, without the need to perform iridotomy or iridectomy, neither of which deal with the root cause of the AACG attack. I can find reference to only four other eyes undergoing lens extraction and IOL implantation as treatment for AACG. ${ }^{10}$ In contrast to this study, three of these had white, mature, and intumescent cataracts, while in the fourth patient AACG was precipitated by preoperative pupillary dilatation prior to routine cataract surgery. All eyes had peripheral iridectomy at the time of cataract extraction. Three eyes attained a VA of $6 / 12$ and one of $6 / 9$. There was no corneal decompensation or increased surgical morbidity. All eyes had a normal IOP, but all were on treatment with topical timolol long term. It would appear that cataract extraction with IOL implantation is an appropriate mode of treatment for AACG and allows early visual rehabilitation. Further evaluation of this method is needed.

Three patients suffered a second episode of AACG despite initially patent iridotomies. This mirrors the experience of Gray et al, ${ }^{1}$ though in my study two fellow eyes and only one AACG eye were involved. All occurred within three weeks of laser treatment, and iridotomies were noted to be closed in all three. Transient closure of initially patent Nd-YAG laser iridotomies has been reported in $6.7 \%$ of eyes for the first three weeks following iridotomy. " Late failure of iridotomy by pigment epithelial proliferation was noted in $3-10 \%$ of eyes in the first three months after treatment. ${ }^{11-13}$ Stromal healing accounted for a further $6 \%$ closure rate. Wishart and Hitchings ${ }^{12}$ stress the importance of a large iridotomy to prevent late failure, as nine out of 10 late failures in the series had an iridotomy diameter of $150 \mu \mathrm{m}$ or less. Wise ${ }^{14}$ has described a low energy linear incision method of iridotomy in order to provide large iridotomies of controllable size. The method uses the Wise 103 dioptre iridotomy lens ${ }^{15}$ and involves cutting individual iris fibres across iris tension lines.

Quigley $^{16}$ recommended provocative testing routinely after iridotomy, and Gray et al suggested that provocative testing should be included in the early follow-up of all patients. However, Wishart and Hitchings ${ }^{12}$ found that provocative testing did not identify those iridotomies which subsequently failed.

This study confirms that YAG laser iridotomy may be inadequate to prevent recurrent AACG but also shows that it may be inadequate as prophylaxis against AACG in previously healthy fellow eyes. Provocative testing may be of benefit in identifying eyes in which iridotomies have closed but may not be useful in identifying those which will close in future. Careful observation at frequent intervals in the first six weeks following treatment may prove as effective as provocative testing while avoiding the risk of iatrogenic AACG.

1 Gray RH, Hoare Nairne J, Ayliffe WHR. Efficacy of Nd-YAG laser iridotomies in acute angle closure glaucoma. $\mathrm{Br}$ f Ophthalmol 1989; 73: 182-5.

2 Krupin T, Mitchell KB, Johnson MF, Becker B. The long term effects of iridectomy for primary acute angle-closure glaucoma. Am f Ophthalmol 1978; 86: 506-9.

3 Lowe RF. Primary angle-closure glaucoma: Investigations after surgery for pupil block. Am $\mathcal{F}$ Ophthalmol 1964; 57: 931-8.

4 Lowe RF. Primary angle-closure glaucoma: investigations using $10 \%$ phenylephrine eyedrops. Am F Ophthalmol 1965; 60: 415-9.

5 Lowe RF. Primary angle-closure glaucoma: postoperative acute glaucoma after phenylephrine eyedrops. Am $\mathcal{f} O \mathrm{ph}$ thalmol 1968; 65: 552-4.

6 Godel V, Stein R, Feiler-Ofry V. Angle closure glaucoma following peripheral iridectomy and mydriasis. Am $\mathcal{f} O p h$ thalmol 1968; 65: 555-60.

7 Hass J, Scheie H. Peripheral iridectomy in narrow angle glaucoma. Ophthalmology 1957; 55: 59-63.

8 Lowe RF. Causes of shallow anterior chamber in primary angle-closure glaucoma. Am F Ophthalmol 1969; 67: 87-93.

9 Godel V, Regenbogen L. Cataractogenic factors in patients with primary angle-closure glaucoma after peripheral with primary angle-closure glaucoma after
iridectomy. $A m \mathcal{F}$ Ophthalmol $1977 ; 83: 180-4$.

10 Civerchia L, Balent A. Intraocular lens implantation in acute angle closure glaucoma associated with cataract. $\mathcal{F} \mathrm{Am}$ Intraocular Implant Soc 1985; 11: 171-3.

11 Naveh N, Zborowsky-Gutman L, Blumenthal M. Nd-YAG laser iridotomy in angle closure glaucoma: a preliminary study. Br f Ophthalmol 1987; 71: 257-61.

12 Wishart P, Hitchings R. Neodymium YAG and dye laser iridotomy - a comparative study. Trans Ophthalmol Soc UK 1986; 105 : $521-40$.

13 Brazier D. Neodymium YAG laser iridotomy. $f R$ Soc Med 1986; 79: 658-60.

14 Wise J. Low-energy linear incision neodymium:YAG laser iridotomy versus linear incision argon laser iridotomy. Ophthalmology 1987; 94: 1531-7.

15 Wise J. A high efficiency laser iridotomy-sphincterotomy lens. Am $\mathcal{F}$ Ophthalmol 1986; 101: 546-53.

16 Quigley HA. Long-term follow-up of laser iridotomy. Ophthalmology 1981; 88: 218-24. 